\title{
12
}

\section{Creating a Culture of Formative Assessment: The Teaching Excellence and Assessment Partnership Project}

\author{
Roseanna G. Ross \\ Anthony Schwaller \\ Jenine Helmin \\ St. Cloud State University
}

In a year-long, grant-supported collaborative effort, St. Cloud State University's Assessment Office and Faculty Center for Teaching Excellence created a Classroom Assessment Teclmiques (CATs) faculty development project. This project was targeted at departments across campus at St. Cloud State University, with the intent of creating a university climate of formative assessment while improving teaching and learming. This article describes the purposes, stages of implementation, and results of the project as measured by a pre-test and post-test survey. The pre-and post-lest survoys indicate that the project was bighly effective in impacting the use of CATs among participants and their departmental colleagues.

\section{INTRODUCTION}

The Partnership

St. Cloud State University has both a Faculty Center for Teaching Excellence and an Assessment Office. Although these two offices were established to operate independently, it was recognized that projects dealing with both improvements of teaching and learning as well as assessment in the classroom of student learning offer rich opportunities for collaboration. This project was an initial effort at collaboration between the two offices. The Teaching Excellence and Assessment Partnership Project 
entitled "Enhancing Student Learning Through Formative Assessment" was designed to assist faculty in developing and integrating strategies for obtaining useful feedback about student learning and teaching effectiveness. This project was intended to enhance classroom learning through formative assessment using Classroom Assessment Techniques, also called CATs. CATs are designed to involve and empower both teachers and students to improve the quality of learning in the classroom. In addition, CATs can become part of a classroom research plan for faculty.

The purpose of the Faculty Center for Teaching Excellence is to promote useful conversations about good teaching by providing resources and strategies to support, strengthen, and recognize excellent and innovative teaching for active learning. The mission of the Assessment Office is to encourage and facilitate assessment practices on campus within all programs and departments. The directors of both the Faculty Center for Teaching Excellence and the Assessment Office felt that a project dealing with formative assessment might, in fact, help to meet various goals and objectives in both offices. Thus, the two offices worked together to secure a grant and develop this formative assessment project to improve teaching and learning.

\section{Statement of the Problem}

The Assessment Office recognized that there was not a campus culture of assessment at SCSU-faculty seemed wary of the word "assessment" itself and were only aware of the summative nature of assessment. The Assessment Office felt that there was a need for further education about the many forms, styles, and types of assessment. The Assessment Office also identified a lack of support within departments for faculty to take the initiative in assessment efforts within their own classrooms.

In addition to these stated problems, the Faculty Center for Teaching Excellence wanted the faculty to see more clearly the connection between formative assessment and the potential for enhanced teaching and student learning in the classroom. This partnership project provided a strategy for meeting goals and objectives for both offices.

\section{Definition of Terms}

To help the reader understand the meaning and value of this project, several terms need to be defined. These terms include the definitions of formative assessment, classroom assessment techniques, and classroom research, which are drawn from the work of Angelo and Cross (1993) and Cross and Steadman (1996). 
- Formative Assessment. Unlike summative approaches to assessment, which are intended to provide evidence for evaluating or grading students at the end of a learning experience, formative assessment in the classroom involves students and teachers in the continuous monitoring of students' learning throughout the term.

- Classroom Assessment Techniques (CATs). CATs are a formative assessment tool intended to be learner-centered, teacher-directed, and context specific. CATs are simple, yet systematic classroom teaching strategies that provide faculty with feedback about their effectiveness as teachers and give the teacher a measure of the students' progress as learners (Angelo \& Cross, 1993). Faculty can then use this information to redirect their teaching strategies to help students make their learning more efficient and more effective. CATs can be considered an assessment technique as well as a teaching strategy.

- Classroom Research. Classroom research refers to a teacher's conscious planning, gathering, analysis, and evaluation of feedback from students for the purpose of appraising the effectiveness of some part of any course being taught by a faculty member. Classroom research is, more often than not, qualitative rather than quantitative. Classroom research is formative rather than summative, learner-centered rather than teacher-centered, and beneficial to the students who give feedback as well as to the teacher who asks for it. Classroom research should be thought of as an ongoing process rather than just a single event (Cross \& Steadman, 1996).

\section{Design of the Project}

\section{Goals of the Project}

The goals of this collaborative project are directly related to the mission and goals of both the Faculty Center for Teaching Excellence and the Assessment Office as well as to the problems that have been identified by these two offices in the "Statement of the Problem." These goals include:

1) To promote formative assessment for enhanced classroom teaching and learning.

2) To teach university faculty about CATs.

3) To create a culture of formative assessment on campus. 


\section{Objectives of the Project}

From the development of the stated goals, the authors developed specific objectives that were used to guide the design, implementation, and assessment of the project. Objectives of the project included:

1) To secure involvement of a large number of departments from a variety of colleges. Each department would then identify departmental representatives to participate in the project (the grant limited participation to 15 departments).

2) To perform a pre-project, "profile" survey of participating departments.

3) To teach CATs and formative assessment techniques to representatives of those selected departments.

4) To support the participants' use of CATs within their respective classrooms throughout the year.

5) To encourage the participants to share insights from the project with colleagues in their departments.

6) To analyze the impact of CATs training and application on participants and their departments.

\section{Description of the Project}

Based upon these goals and objectives, the project was organized around ten stages of development and implementation.

Stage one: Introduction, promotion, and design of project. To market and publicize the project across the university campus, we developed a brochure (which announced the project and introduced the concept of formative assessment and CATs) and disseminated it to all faculty within the university. In addition, the directors of the project met with each of the college deans and chairpersons to define and explain the purposes of the project. The goal of the Faculty Center for Teaching Excellence and the Assessment Office was to secure participation and faculty representation from at least 15 departments. At the same time, the authors recognized that campus-wide distribution of the brochure was an initial step in educating the campus community on formative assessment. During this initial stage, two Minnesota consultants, recommended by Thomas Angelo as experts on CATs, were engaged to help with the project. These two consultants were asked to help design the formative assessment profile survey (which was to be used as a pre- and post-test), to present a university-wide address on assessment, and to facilitate two workshops for the project participants-a workshop at the beginning of the project and a follow-up workshop half-way through the project. 
Stage two: Participant application and selection. After the project was adequately advertised, application forms were sent to approximately 700 faculty and 70 departments or programs (see Appendix 1 for letter to departments). The application form was designed to encourage at least three members from any one particular academic department or program to become involved in this project. Within the application form, the applicants were also asked to describe how they proposed to disseminate information learned within the project to the remaining members of their department. We made the dissemination plan a major requirement of the project in order to encourage those participating in the project to begin discussions and communications with other faculty members within their department about formative assessment and CATs. Such discussions were imperative to expanding the reach of the program and to creating a departmental support system for future use of CATs. It should be noted that each faculty member who was selected for the project was provided with an honorarium within the grant of $\$ 250$. As it turned out, 44 faculty members were part of the project, and 13 departments or programs were represented. Of the 44 faculty members, eight decided to be involved as individuals not necessarily associated with a department.

Stage tbree: Participant and department profile survey (as pre-test). Once the faculty and departments were selected, faculty from all selected departments or programs (or individual faculty members) were asked to complete a formative assessment profile survey (see Appendix 2). The survey was designed to identify the attitudes of participating faculty concerning classroom assessment and research as part of their teaching practice. This survey was given both before the project began (to establish a base-line) and again after the project was completed (for comparison purposes). This survey was designed by the two outside consultants and contained questions about faculty members' familiarity with formative assessment, attitudes about assessment, and use of activities to enhance formative assessment in the classroom. A 1-to-5 Likert scale was used to help identify these attitudes. In addition, various demographic data were collected to help in classifying faculty respondents.

Stage four: University-wide address on classroom researcb. In February of the project year, the two consultants were invited to address the university faculty on the project and specific concepts dealing with assessment. Their presentation, "Enriching Your Teaching: Classroom Research through Classroom Assessment," was interactive and focused on 
avenues for involvement in classroom research and assessment. The purpose of the presentation was to kick off the project and to help educate faculty campus-wide on classroom research and assessment. Although this was an open address, participating faculty selected for the project were required to attend as part of their training in the project.

Stage five: Initial training of participants. Immediately following the university-wide address, the 44 individuals selected for the project met with the two consultants to learn more about the value and purposes of formative classroom assessment and the use of CATs. This four-hour, interactive workshop was designed to show faculty how Classroom Assessment Techniques can be used to improve the teaching and learning environment. During this time, faculty identified specific CATs that could be used in their courses over the next three months.

Stage six: Implementation of CATs. For approximately three months after the initial university-wide address and the workshop with the consultants, faculty selected for the project began the process of implementing CATs within their classrooms. It was during this time that faculty actually experienced the value of CATs and formative assessment. A brown-bag lunch was held for any participant wanting additional support during this time. Each participant received a copy of Classroom Assessment Techniques: A Handbook for College Teachers (Angelo \& Cross, 1993). The 13 participating departments also received a copy of Classroom Research: Implementing the Scholarship of Teaching (Cross \& Steadman, 1996). Occasional communications were sent from the Center to encourage continued participation.

Stage seven: Continued training of participants. In April, the project participants met again in a four-hour, follow-up session to work with the two consultants and to share their successes and failures with CATs and formative assessment. This time was also used to correct any misconceptions about CATs and formative assessment. It was anticipated that based upon this follow-up session the faculty in the project could continue improving their use of CATs in their classrooms.

Stage eigbt: Dissemination in departments. Near the end of the spring term, project participants disseminated the information learned from the project to other faculty members within their departments and/or programs. The method used for dissemination was originally described in 
their application form and was one criterion in the selection process for participation in the project. These dissemination methods included presentations at faculty meetings, writing and circulating reports or specific classroom applications, use of email interaction with colleagues, and writing newsletter articles.

Stage nine: Participant and department profile survey (as post-test). After completing all departmental dissemination efforts, project participants, as well as the members of their departments, were given the formative assessment profile survey as a post-test. The data from the pre- and post-test surveys would later be used to help assess the impact of this particular project.

Stage ten: Reporting of classroom implementation and continued support. Finally, each participating member of the project submitted either a one-page report to the Faculty Center for Teaching Excellence on the implementation of CATs in the classroom or wrote an article for publication in the Minnesota State Colleges and Universities Center for Teaching and Learning publication entitled Open to Change.

To extend the impact of the project beyond the first year, in the subsequent year participating faculty presented information about their use of CATs in Center-sponsored campus forums. Center representatives and participants have also shared the project at state and national conferences. Participant reports on the use of CATs are available to faculty as a resource through the Center and will soon be published on the Center's web page (http://www.stcloudstate.edu/ teaching/index.html).

\section{Design of the Study Using Survey Data}

The pre- and post-test survey on the knowledge of, attitudes toward, and behavior in using CATs and formative assessment was ideal for comparing several groups of faculty involved with the project. Mean and $t$-Test analyses were conducted on the survey data. The mean is the average and the $t$-Test is the comparison of means (the greater the difference between the means, the greater the difference between the groups). The significance was measured at the .05 and .01 levels.

In this project, two groups were tested in various comparisons to each other. The first group, called "participants," were those departmental representatives and individual faculty specifically selected for the project. These participants attended the two workshops on CATs and formative assessment and implemented this knowledge in a specific 
course(s). The second group, called "colleagues," were those additional faculty within the 13 selected departments. The "colleagues" were not directly involved in the project but may have attended the universitywide address and/or may have been involved in departmental/program dissemination efforts. Four tests were designed to compare the attitude of these two groups toward CATs and formative assessment.

- Test 1 is a comparison of all respondents, including the "participants" and the departmental "colleagues," simply comparing the pre-test survey results to the post-test survey results of all faculty involved in any way with the project.

- Test 2 is a comparison of only the "participants," or those directly involved with the project, by comparing their pre-test survey results to their post-test survey results.

- Test 3 is a comparison of only those "colleagues," or those departmental faculty not directly involved with the project, comparing their pre-test survey results to their post-test survey results.

- Test 4 is a comparison of the "participants" to the "colleagues," examining whether there was a significant difference in change of attitude and behavior between the two groups.

\section{Results of the Project}

\section{Participant Numbers}

Based upon the participant numbers, the project advertising was a success. At the beginning of the project, during the university-wide address, a total of 67 university faculty attended the presentation (this included participating department representatives and their departmental colleagues). A total of 44 faculty participated in the project training and CATs implementation in courses. Of this number, 36 faculty "participants" were identified as departmental representatives, representing 13 departments. (The remaining eight faculty participants-from eight different disciplines-requested to be involved as individuals since their departments chose not to participate. Because funds were available, and their participation fit the overarching goals of the project, it was decided to support their participation and request dissemination in professional arenas other than their departments.) 


\section{Survey Results}

The pre- and post-test surveys indicated that the 44 participants' knowledge, attitudes, and behaviors around CATs had been positively impacted at significant levels of .01 and/or .05 . The surveys also indicated that this project had a slight impact on colleagues' attitudes toward CATs. The questions showing significant change in knowledge, attitude, or behavior for each of the groups are described below (see Appendix 3 for the table reporting the probabilities for all four tests).

Test 1: A comparison of all respondents' (participants and colleagues) pre-and post-test survey responses. A comparison of the mean scores on the pre- and post-test surveys shows that these faculty reported an increase in the following activities at the conclusion of the CATs project:

- Attend more presentations and read books on assessment (survey question 5)

- Believe in more ongoing assessment (survey question 14)

- Structure time within the class for written feedback (survey question 16)

- Analyze and discuss written feedback with students (survey question 17)

Test 2: A comparison of the participants' pre- and post-test survey responses. A comparison of the mean scores on the pre- and post-test surveys shows that these faculty reported an increase in the following activities at the conclusion of the CATs project:

- Attend more presentations and read books on assessment (survey question 5)

- Believe more information is needed than just at end of term (survey question 14)

- Have discussions with students about assignment effectiveness (survey question 15)

- Structure time within the class for written feedback (survey question 16)

- Analyze and discuss written feedback with students (survey question 17)

- Have discussed written feedback from classes with colleagues (survey question 18) 
Test 3: A comparison of the colleagues' pre- and post-test survey responses. A comparison of the mean scores on the pre- and post-test surveys shows that these faculty reported an increase in the following activities at the conclusion of the CATs project:

- Analyze and discuss written feedback with students (survey question 17)

Test 4: A comparison of participants' responses witb colleagues' responses. A comparison of participant and colleague mean scores on the pre- and post-test surveys shows that participants, in comparison to colleagues, reported a significantly greater increase in the following activities:

- Attend presentations and read books on assessment (survey question 5)

- Believe in ongoing assessment (survey question 6)

- Believe in making the effort to gather data (survey question 7)

- Believe information is needed more than just at end of the term (survey question 8)

- Seek written feedback other than at end of the term (survey question 9)

- Believe feedback should be sought frequently (survey question 10)

- Are comfortable taking time for discussions about class effectiveness (survey question 11)

- Are willing to change course in response to feedback (survey question 12)

- Seek written feedback other than end of term (survey question 14)

- Analyze and discuss written feedback with students (question 17)

\section{Participant Comments While Using CATs}

During the second workshop in April, participants were asked to comment on their experience with their use of CATs in the classroom up to that point. The following statements represent a summary of many of project participants' responses:

- CATs act as a classroom activator, leading to positive and broad interaction among students and faculty. 
- CATs help to change student and teacher expectations, to determine where students are, and to adjust accordingly.

- CATs help to increase student ownership of their learning, taking more responsibility for their learning.

- CATs help to develop an unexpected depth of understanding and creativity in the teaching/learning process.

- CATs help to show how perceptions differ between students and faculty.

\section{Conclusions}

After reviewing the results and observing the implementation and completion of the project, the project directors feel confident in making several concluding statements. First, it appears that the project helped to bring the concept of classroom assessment to the forefront within the university setting. With the major promotional campaign, it was inevitable that faculty, campus-wide, would be more aware of formative assessment in general and Classroom Assessment Techniques in particular. The project was also instrumental in facilitating faculty conversations about assessment, thanks in large part to the participation of departmental colleagues during dissemination efforts. As reported in the surveys, faculty participation in the project directly enhanced instruction in the classroom. Finally, the project functioned to bring the Faculty Center for Teaching Excellence and the Assessment Office together in a collaborative effort, which, in turn, helped faculty to see assessment as less intimidating while impacting the teaching and learning atmosphere within the university.

The following recommendations may help to improve similar projects that other universities may undertake.

1) Continued communications with the project participants is necessary throughout the year.

2) All communication to faculty needs to be clear and concise.

3) Be flexible so that some faculty not interested in working with colleagues can work individually with such a project.

4) Understand that there is not a common paradigm on campus about assessment, its definitions, purposes, etc.

5) Understand that all faculty do not have the same understanding of student learning and teaching methodology.

6) Remember that faculty have many activities throughout a school 
year and that this project is just another professional activity that they are incorporating into their daily schedules.

7) Be sure that the project directors communicate effectively and meet on a regular basis.

8) Remember that effective communication is critical between the project directors and the consultants. The consultants need to clearly understand the goals of the project.

9) The survey for pre- and post-testing needs to be carefully and clearly developed.

10) When selecting departments for the project, try to get representation from across all colleges within the university.

\section{ACKNOWLEDGMENTS}

The authors wish to thank Connie Stack and Joel Peterson for their work as faculty consultants and workshop presenters for this project and Laurel Malikowski for her assistance in conducting the project.

\section{REFERENCES}

Angelo, T. A., \& Cross, K. P. (1993). Classroom assessment techniques: $A$ bandbook for college teachers (2nd ed.). San Francisco, CA: Jossey-Bass.

Cross, K. P., \& Steadman, M. H. (1996). Classroom research: Implementing the scholarship of teaching. San Francisco, CA: Jossey-Bass.

[This paper was initially presented in Fall 1997 at the Professional and Organizational Development Network in Higher Education Conference, at the MnSCU Center for Teaching and Learning Conference, and at a St. Cloud State University Faculty Forum.]

\section{Contact:}

Roseanna G. Ross

Faculty Center for Teaching Excellence

St. Cloud State University

720 Fourth Avenue South

St. Cloud, MN 56301-4498

(320) 654-5282

(320) 255-3217 (FAX)

teaching@StCloudState.edu 
Roseanna G. Ross, is professor of, and internship director in, Speech Communication and has been Director of St. Cloud State University's Faculty Center for Teaching Excellence since 1995. Her research interests include experiential learning (co-author of the Internship as Partnership Handbook series published through the National Society for Experiential Education) and conflict management (co-author of the Ross-DeWine Conflict Management Message Style Instrument).

Anthony Schwaller is Professor and Chair of the Department of Environmental and Technological Studies at St. Cloud State University and was Assessment Director at St. Cloud State University from 1994 to 1998. His related research interests include teaching methodology. He co-authored the textbook entitled Instructional Strategies for Teclonology Education, and he has written numerous articles and chapters for other textbooks concerning teaching, learning, and delivery systems for technology teachers.

Jenine Helmin was the Graduate Assistant for the Teaching Excellence Center and Assessment Partnership Project. Helmin's master's thesis, Classroom Assessment Tecloniques: Perceptions of Effectiveness for Teaching Diverse Student Populations in Higher Education, combined her interests of teaching, assessment, and cultural diversity. She currently teaches in the Department of Women's Studies at St. Cloud State University. 


\section{APPENDIX 12.1}

ST. CLOUD STATE UNIVERSITY

720 Fourth Avenue South

St. Cloud, MN 56301-4498

Phone (320) 654-5282

(320) 202-0907
TEACHING EXCELLENCE AND ASSESSMENT PARTNERSHIP

Enbancing Student Leaming

Through Formative Assessment

December 9, 1996

Department Chairs and Program Directors:

Your department or program has a unique opportunity for enhancing teaching effectiveness and student learning! The Faculty Center for Teaching Excellence and the Assessment Office have developed a project called "the Teaching Excellence and Assessment Partnership: Enhancing Student Learning Through Formative Assessment," funded by a Q-7 grant. Your department/program is invited to join our efforts to encourage formative assessment (a teaching technique used to monitor students'learning throughout the term) to help improve the quality of teaching in your courses. We are requesting that your department/program select two to three faculty members, who are seriously committed to teaching effectiveness and student learning, to become involved in this project.

To enhance the quality of classroom teaching within your department/program, faculty representatives selected for the project will work with consultants and learn about and integrate formative assessment. During this project, the faculty representatives are expected to share the formative assessment techniques called CATs (Classroom Assessment Techniques) with other faculty in their department/program. The goal of this project is to integrate CATs into your department's/program's classrooms with the help of the chosen faculty representatives.

Participating departments/programs will be requested to complete a simple preand post-formative assessment profile survey. The survey is to provide evidence of project effectiveness and to assist consultants in working with individual faculty.

To launch this project, all faculty are invited to a university-wide address entitled, Enriching Your Teaching: Classroom Rescarch Through Classroom Assessment, on February 4, from 10:00 to 11:30 a.m., Atwood Center. This address will focus on ways in which faculty can become involved in classroom research, and how classroom research is related to formative assessment and student learning. See enclosed materials for more detailed information. 
This is an opportunity for departments/programs to utilize formative assessment and continue to create a culture of teaching excellence at SCSU. Your support is encouraged because, "assessment is most effective when undertaken in an environment that is receptive, supportive, and enabling" (Assessment in Practice, 1996).

Please find enclosed project and application materials.

Thank you,

Roseanna G. Ross and Tony Schwaller

The Teaching Excellence and Assessment Partnership

Jbh: enclosures 


\section{APPENDIX 12.2}

\section{CLASSROOM ASSESSMENT AND RESEARCH FACULTY SURVEY}

This survey is designed to gather anonymous aggregate data from faculty in three areas:

1. Familiarity with the concepts of classroom assessment and classroom research.

2. Attitudes toward classroom assessment and research as a part of teaching practice.

3. Extent to which classroom assessment and research activities are used in regular teaching practice.

The survey begins with some demographic questions to be used to examine possible statistical correlations. Although the data will be aggregated, some of the analysis will be reported as related to departments or programs. Please record each answer on the line provided.

\section{DEMOGRAPHICS}

1. Did you submit an application to participate in the Q-7 grant funded project and workshop on Feb. 4 and April 14, 1997? (select one)
a. Yes
b. No

2. How many years have you been teaching in a university/college setting? (select one)
a. $1-2$
b. 3-6
c. $7-10$
d. 11-15
e. 16 or more

3. Which statement best reflects your background in learning theory? (select one)

a. I have a degree in a field involving rigorous study of learning theory and teaching practice.

b. I have taken some courses in learning theory and teaching practice. 
c. I have taken no courses in learning theory, but I attend conferences and read books and articles focused on learning theory and teaching practice.

d. I have taken no courses in learning theory and have little interest in readings and workshops on improving teaching unless it is directly related to teaching in my own field.

e. My educational background and my current professional interests have been focused completely on research in my field, not on teaching.

4. Gender (optional)
a. Female
b. Male

\section{FAMILIARITY WITH CLASSROOM ASSESSMENT AND RESEARCH}

5. Which statement best describes your knowledge of classroom assessment and classroom research? (select one)

a. I am not familiar with any specialized sense of these terms. I can only infer what they refer to from my understand of the terms "classroom," "assessment," and "research."

b. I am familiar with some of the techniques included in classroom assessment (such as "The Muddiest Point" and "The Minute Paper"), but l've never read about or attended presentations on classroom assessment or research.

c. I have attended presentations and/or read some articles on classroom assessment or research.

d. I have read and used the book Classroom Assessment Tecbniques-by Thomas Angelo and Patricia Cross-extensively.

e. I have given presentations and/or written articles on classroom assessment and/or classroom research.

The remainder of questions will use the Likert Scale.

Please indicate the degree to which you agree or disagree with the following statements according to the following Likert Scale:

$$
\begin{aligned}
& 1=\text { Strongly disagree } \\
& 2=\text { Somewhat disagree } \\
& 3=\text { Neither agree nor disagree } \\
& 4=\text { Somewhat agree } \\
& 5=\text { Strongly agree }
\end{aligned}
$$




\section{ATTITUDES TOWARD CLASSROOM ASSESSMENT AND RESEARCH AS A PART OF TEACHING PRACTICE}

6. I believe that, in the college setting, the only appropriate use of assessment is to determine the degree to which students have mastered course content and required skills.

7. I believe that, in the college setting, it is important for faculty to make a conscious effort to gather assessment data specifically on the effectiveness of their teaching techniques as well as to gather assessment data on student mastery of course content.

8. I believe that student course evaluations at the end of the term, together with students' grades, provide sufficient information for me to assess the effectiveness of my teaching techniques.

9. I believe it is a good idea to take the time at a number of points in the term to ask students, anonymously, to provide written feedback to help me assess the effectiveness of my teaching strategies.

10. Neither I nor my students can afford to take the time away from course content to write responses to questions about the effectiveness of various aspects of the class.

Continue using the Likert Scale:

$$
\begin{aligned}
& 1=\text { Strongly disagree } \\
& 2=\text { Somewhat disagree } \\
& 3=\text { Neither agree nor disagree } \\
& 4=\text { Somewhat agree } \\
& 5=\text { Strongly agree }
\end{aligned}
$$

11. I am comfortable taking time during the term to hold discussions in class about the effectiveness of class activities and assignments, and I welcome suggestions for improvement.

12. My courses are so complexly structured and my time so short that I really can't afford to change anything in midcourse; therefore, I don't see any value in asking for student feedback on the course until the end-of-term course evaluations.

13. I believe it is necessary that, when I ask students to give me written feedback on any aspect of a course, it should be done anonymously. 
EXTENT TO WHICH CLASSROOM ASSESSMENT AND

RESEARCH ACTIVITIES ARE USED IN REGULAR TEACHING PRACTICE

14. At present, the only written feedback I get on students' perceptions of the effectiveness of my courses is through the end of term student course evaluation.

15. In my courses, from time to time, we do have discussions about the effectiveness of the assignments and activities, and I welcome students' feedback and suggestions.

16. I structure into my classes time for students to respond in writing to questions about their perceptions of their learning experience in course activities and assignments and/or how to make the course work better.

17. When I do ask students to write down responses to questions about their learning experience, I take time to analyze and discuss the results with class afterwards.

18. I have, from time to time, gathered data from students' anonymous written responses to questions about aspects of my courses and discussed the results with faculty colleagues. 


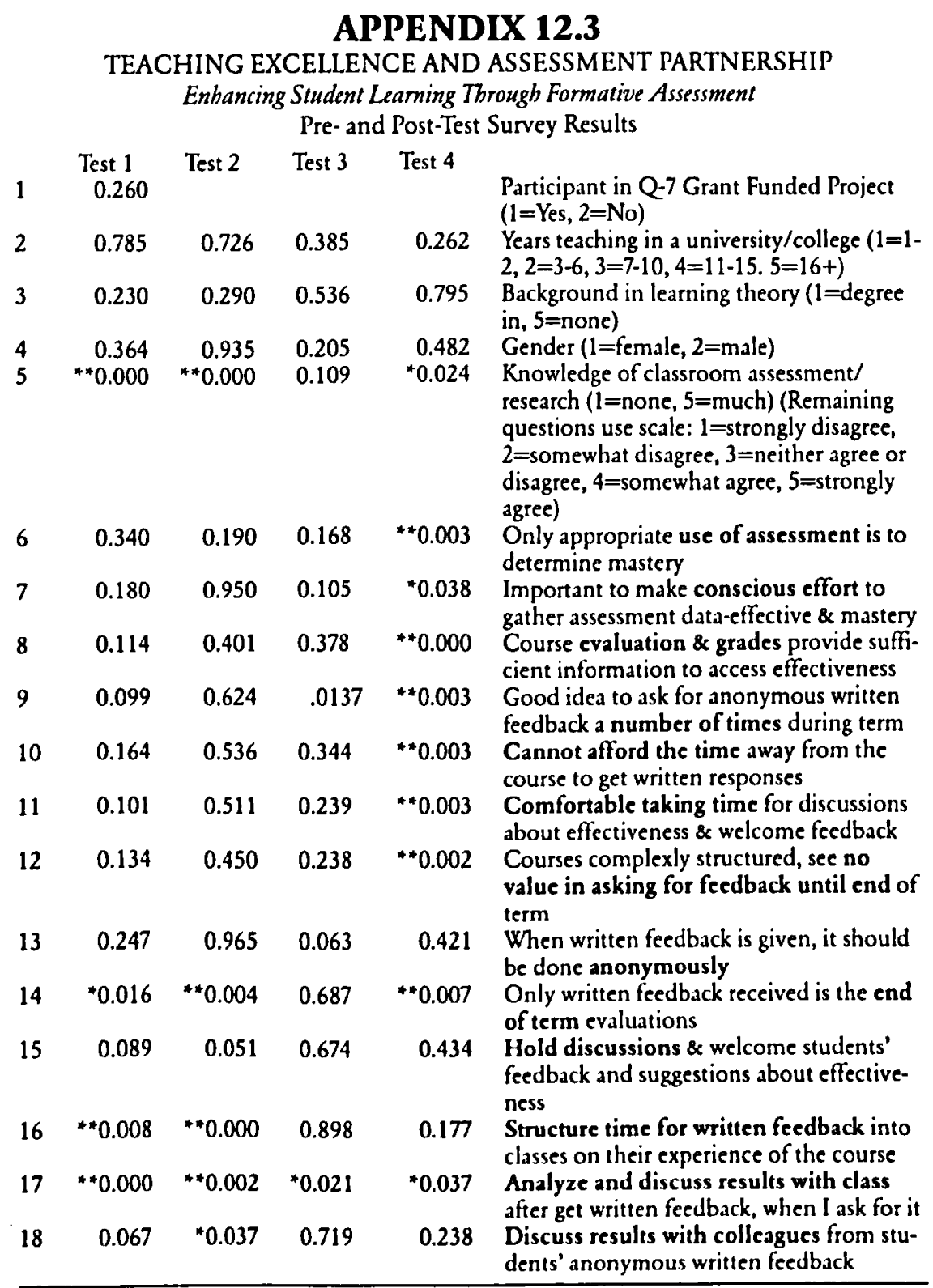

* = significant at the .05 level

** = significant at the 01 level

Test 1: a comparison of all respondent's (participants and members of their departments) pre-test $(n=97)$ and post-test $(n=73)$ survey responses.

Test 2: a comparison of the participants' pre-test $(n=42)$ and post-test $(n=39)$ survey responses.

Test 3: a comparison of the departmental colleagues" pre-test $(n=55)$ and post-test $(n=34)$ survey responses.

Test 4: a comparison of participants' responses $(n=81)$ with department members' survey responses $(n=89)$. 